Article

\title{
Micro-Topography Mapping through Terrestrial LiDAR in Densely Vegetated Coastal Environments
}

\author{
Xukai Zhang ${ }^{1, *}$, Xuelian Meng ${ }^{1,2}{ }^{(}$, , Chunyan $\mathrm{Li}^{2,3}$, Nan Shang ${ }^{1}$, Jiaze Wang ${ }^{4}$, Yaping Xu ${ }^{5}{ }^{\circledR}$, Tao Wu ${ }^{6}$ \\ and Cliff Mugnier ${ }^{7}$
}

check for updates

Citation: Zhang, X.; Meng, X.; Li, C.; Shang, N.; Wang, J.; Xu, Y.; Wu, T.; Mugnier, C. Micro-Topography Mapping through Terrestrial LiDAR in Densely Vegetated Coastal Environments. ISPRS Int. J. Geo-Inf. 2021, 10, 665. https://doi.org/ 10.3390/ijgi10100665

\section{Academic Editors:}

Emmanouil Psomiadis, Konstantinos X. Soulis and Wolfgang Kainz

Received: 9 August 2021

Accepted: 27 September 2021

Published: 1 October 2021

Publisher's Note: MDPI stays neutral with regard to jurisdictional claims in published maps and institutional affiliations.

Copyright: (c) 2021 by the authors. Licensee MDPI, Basel, Switzerland. This article is an open access article distributed under the terms and conditions of the Creative Commons Attribution (CC BY) license (https:/ / creativecommons.org/licenses/by/ $4.0 /)$.
1 Department of Geography \& Anthropology, Louisiana State University, Baton Rouge, LA 70803, USA; smeng@lsu.edu (X.M.); nshang1@lsu.edu (N.S.)

2 Coastal Studies Institute, Louisiana State University, Baton Rouge, LA 70803, USA; cli@lsu.edu

3 Department of Oceanography and Coastal Sciences, Louisiana State University, Baton Rouge, LA 70803, USA

Oak Ridge National Laboratory, Oak Ridge, TN 37830, USA; wangj1@ornl.gov

Department of Plant Sciences, University of Tennessee, Knoxville, TN 37996, USA; yxu86@utk.edu

6 Department of Geography, Zhejiang Normal University, Jinhua 321004, China; twu@zjnu.cn

7 Department of Civil and Environmental Engineering, Louisiana State University, Baton Rouge, LA 70803, USA; cjmce@lsu.edu

* Correspondence: xzhang@archbold-station.org; Tel.: +1-(225)-408-9781

\begin{abstract}
Terrestrial Light Detection And Ranging (LiDAR), also referred to as terrestrial laser scanning (TLS), has gained increasing popularity in terms of providing highly detailed microtopography with millimetric measurement precision and accuracy. However, accurately depicting terrain under dense vegetation remains a challenge due to the blocking of signal and the lack of nearby ground. Without dependence on historical data, this research proposes a novel and rapid solution to map densely vegetated coastal environments by integrating terrestrial LiDAR with GPS surveys. To verify and improve the application of terrestrial LiDAR in coastal dense-vegetation areas, we set up eleven scans of terrestrial LiDAR in October 2015 along a sand berm with vegetation planted in Plaquemines Parish of Louisiana. At the same time, 2634 GPS points were collected for the accuracy assessment of terrain mapping and terrain correction. Object-oriented classification was applied to classify the whole berm into tall vegetation, low vegetation and bare ground, with an overall accuracy of $92.7 \%$ and a kappa value of 0.89 . Based on the classification results, terrain correction was conducted for the tall-vegetation and low-vegetation areas, respectively. An adaptive correction factor was applied to the tall-vegetation area, and the 95th percentile error was calculated as the correction factor from the surface model instead of the terrain model for the low-vegetation area. The terrain correction method successfully reduced the mean error from $0.407 \mathrm{~m}$ to $-0.068 \mathrm{~m}$ (RMSE errors from $0.425 \mathrm{~m}$ to $0.146 \mathrm{~m}$ ) in low vegetation and from $0.993 \mathrm{~m}$ to $-0.098 \mathrm{~m}$ (RMSE from $1.070 \mathrm{~m}$ to $0.144 \mathrm{~m}$ ) in tall vegetation.
\end{abstract}

Keywords: terrestrial LiDAR; mapping micro-topography; dense vegetation; coastal environments

\section{Introduction}

Accurate topographic datasets are increasingly needed to detect rapid coastal morphological changes [1], which are critical for performing a reliable simulation of coastal erosion [2] and predicting areas at risk of storm-surge flooding [3]. Timely topographic mapping for the assessment of changes in coastal morphology following disturbance (e.g., floods, storm surges and hurricanes) helps understand the sustainability of coastal communities, structures and ecosystems [4]. Elevation profiles, measured by total station, leveling instrument, and global position system (GPS) surveys in representative locations, are commonly used for coastal topographic mapping and analysis [5-7]. However, considering the spatial heterogeneity of coastal lands and hydrodynamics, analysis based on a limited number of profiles may be insufficient for an accurate survey of morphological changes 
over the large area [8]. Discrete profile samples may overlook areas with severe sediment change because of the necessity to predetermine profile locations for periodical surveys combined with the difficulty in predicting locations of severe change. High-accuracy topographic mapping requires a large array of sensors or more measurements [9], which can be challenging and costly in field environments using these discrete measurement methods.

In recent decades, with advanced remote sensing developments, various remotely sensed data have played an essential role in mapping and modeling coastal morphology [10]. Satellite images, such as Landsat thematic mapper (TM) images, are widely applied in coastal morphological research studies [11], but they are restricted to large-scale studies because of the relatively low spatial and temporal resolution. Additionally, a growing number of remotely sensed methods, such as photogrammetric stereo mapping [12], radar [13] and Light Detection And Ranging (LiDAR) [14], have been used for coastal morphological analysis and demonstrated superior advantages over discrete sampling methods. However, accurate topographic mapping in coastal environments remains challenging for areas covered by dense vegetation that helps to stabilize sediment and prevent land loss $[15,16]$. Previous studies have shown that such vegetation as trees, shrubs, and grasses can cause significant errors in terrain mapping [17-20] that lead to error propagation in the following sediment dynamics and morphological change analysis [21,22]. Hutton and Brazier (2012) [22] examined the impact of uncertainty in the shuttle radar topography mission (SRTM; $90 \mathrm{~m}$ resolution for global and $30 \mathrm{~m}$ for the United States) on topographic indices and found significant impacts on watershed-scale analysis. Others have studied the error propagation in aboveground biomass [23], plant growth [24], and carbon estimation [25].

Among the new remote sensing technologies, terrestrial LiDAR has demonstrated significant advantages for quick and accurate 3D topographical mapping [26], and started to fill the gap between satellite-based remotely sensed mapping and tedious point-based field surveys. Terrestrial LiDAR, also called terrestrial laser scanning, is a portable surveying system mounted on a tripod that can rotate 360 degrees to acquire virtual reality-like color-coded dense point clouds of the surrounding environment. Through positioning the scanner at multiple locations and multi-site registration, the system can extend to large area mapping. In addition, LiDAR technology is well known for producing multiple layers in vegetated areas and provides advantages in characterizing the vertical structures of vegetation. These unique characteristics make the terrestrial LiDAR system a suitable solution to monitor coastal morphological changes and vegetation dynamics and a quickresponse surveying tool for wetland restoration to document landscapes at critical stages, such as before and after wetland restoration or a disturbance (e.g., floods, storm surges, and hurricanes), and for seasonal or annual surveys.

Known as a high-precision and high-resolution mapping tool, the terrestrial LiDAR system provides a rapid and practical approach to map coastal micro-topography, which has a considerable influence on the hydrology, the habitat variability including vegetation patterns, and the functioning of ecosystems [27-29]. However, high uncertainty under dense vegetation remains a significant challenge due to the inability of laser signals to penetrate tall and dense vegetation [30]. Coveney and Fotheringham (2011) [31] explored the terrestrial laser scan error in the presence of dense ground vegetation and clarified the component contributions to elevation error deriving from vegetation occlusion, scan co-registration errors, point-cloud geo-referencing errors and target position definition. Compared with the other impact factors, they found that the error caused by vegetation occlusion was relatively significant. Fan et al. (2014) [32] applied local-highest-point and local-lowest-point filters to derive the vegetation height and the vegetation-induced elevation error, respectively. They found that the elevation error due to ground vegetation is affected by various parameters, principally the vegetation height and density, scan distance, scan resolution and incidence angle.

Large errors of terrain estimation by terrestrial LiDAR in vegetated areas generally lead to an unreliable micro-topography mapping. Low-accuracy micro-topography mapping 
cannot be input for future morphological analysis, so the results derived from terrestrial LiDAR in vegetated environments need further corrections for quality micro-topography mapping. Guarnieri et al. (2009) [33] presented a novel filter scheme for Terrestrial LiDAR point cloud filtering integrated with GPS survey points to define ground points within low and dense vegetation. They separated ground points from vegetation based on the GPS survey points and refined the classification results for dense and sparse vegetation, taking into account the reflectance of laser return intensity. The approach was applied in a tidal marsh environment with continuous vegetation over a gentle slope and the result is reasonable. Rodriguez-Caballero et al. (2016) [34] improved this method by adapting the window size according to different types and sizes of plants. The accuracy of the final DEMs (digital elevation models), which represent the bare-Earth surface without all natural and built features, was improved by $\sim 30 \%$ under dense canopy plants and over $\sim 40 \%$ on the open spaces between plants. Che and Olsen (2017) [35] proposed a fast ground filtering for terrestrial LiDAR data via Scanline Density Analysis. They first separated the ground points, density features and unidentified points based on an analysis of point density within each scanline. Then, they clustered the ground candidates by region growth and further refined the ground points. The approach shows effectiveness and robustness with datasets from both urban and natural environments. Researchers have improved the micro-topography mapping by filtering or terrain correction, but most have focused on sparse or short dense vegetation environments. Nevertheless, how terrestrial LiDAR responds in the densely vegetated coastal environment has not been explored in depth.

This study aims to alleviate the difficulties and challenges in topographic mapping under dense vegetation and develop a new local-adaptive terrain correction method by integrating crown structures from terrestrial LiDAR with limited ground samples from GPS for a portable, flexible and rapid mapping solution.

\section{Study Site and Field Data Collection}

As the state accounting for $80 \%$ of the wetland loss in the United States, Louisiana is experiencing fast wetland loss due to combined factors including sea level rises, salt water intrusion, and human activities [36]. The wetlands on the west side of the Mississippi River near the Barataria Bay in Plaquemines Parish are representative as a land loss area, where large areas of wetlands have disappeared in the past decades [37]. Located at the Buras Boat Harbor, Plaquemines Parish, Louisiana $\left(29^{\circ} 20^{\prime} 51.27^{\prime \prime} \mathrm{N}, 89^{\circ} 32^{\prime} 9.25^{\prime \prime} \mathrm{W}\right)$, the study site suffered severe wetland degradation, as illustrated in Figure $1 \mathrm{~b}, \mathrm{c}$, from 1998 to 2013 . To prevent further wetland loss and protect the safety of levees, the wetland restoration project was performed through the dredging of sediment and the reconstruction of sand berms along the previous wetland bank in August 2014. The surveyed area is the northwest sand berm highlighted in the red rectangle among the three reconstructed berms illustrated in Figure 1d. The sand berm is approximately $380 \mathrm{~m}$ long and $25 \mathrm{~m}$ wide and was reconstructed in 2014 with three types of vegetation planted. After one year, two types of planted vegetation prevailed on the berm. One was the tall and dense smooth cordgrass (spartina alterniflora) growing in low-elevation zones and the other was low seashore paspalum (panicum vaginatum sw) spreading in high-elevation zones near the centerline of the berm. A few other local vegetation species were found to be sparsely scattered in high-elevation zones. 


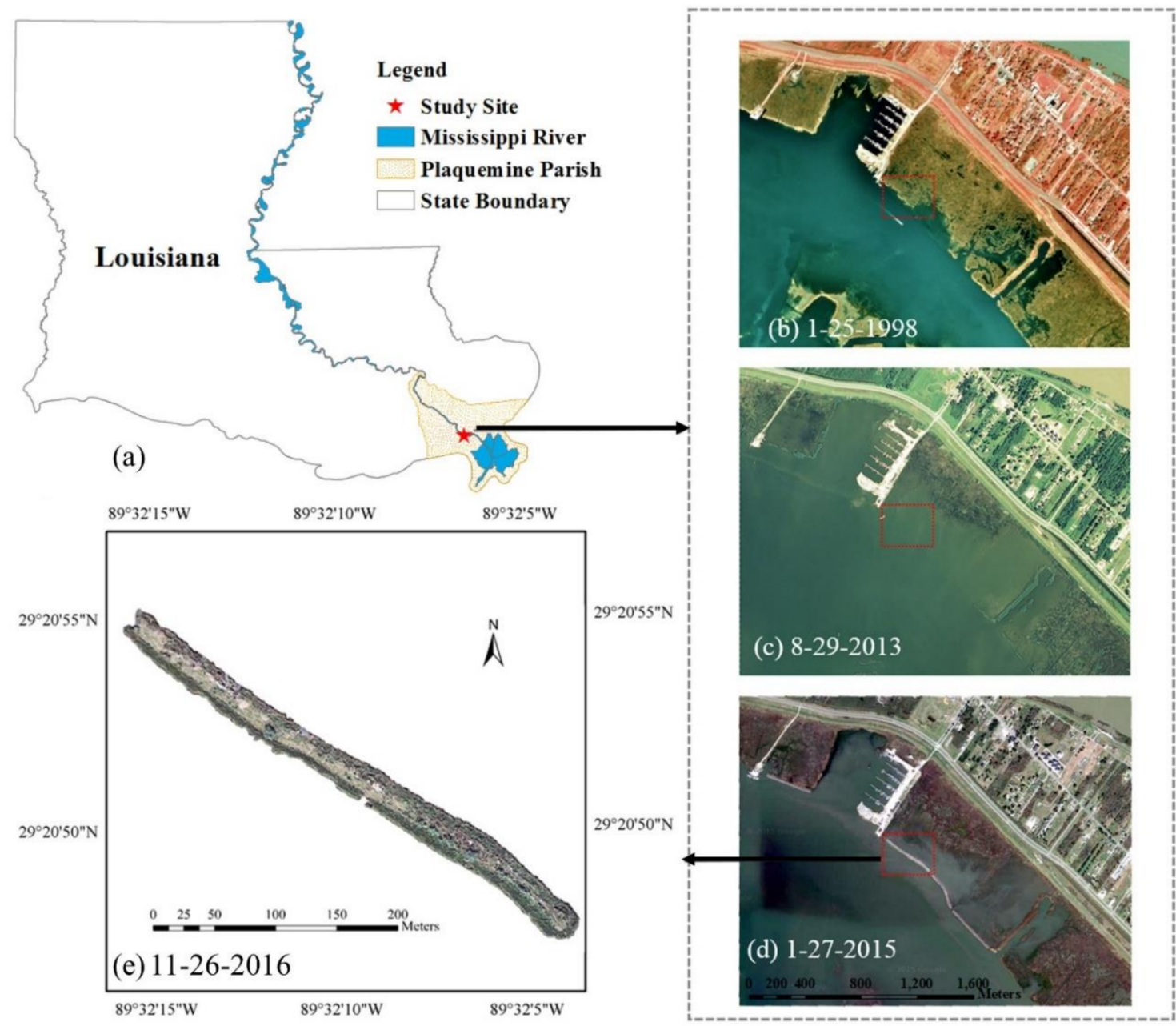

Figure 1. (a) Study site at the Buras Boat Harbor, Plaquemines Parish, Louisiana. The images (b,c) are aerial photographs from the USGS website demonstrating the wetland degradation from 1998 to 2013. The 2015 Google Earth image (d) shows the landscape after berm reconstruction. The image (e) is the georeferenced image acquired in 2016 from Google Earth.

We conducted field data collection on 1 October 2015, using terrestrial LiDAR, with eleven scan stations evenly distributed on areas with bare ground and low vegetation. The terrestrial LiDAR system used in this research is Riegl VZ-1000, with a range measurement precision of $5 \mathrm{~mm}$ and an accuracy of $8 \mathrm{~mm}$ for a $100 \mathrm{~m}$ range. It provides a high-density measurement capability of up to 122,000 measurements/second, a $360^{\circ}$ horizontal and $100^{\circ}$ vertical field of view and a scanning range of $1400 \mathrm{~m}$. A Trimble R10 GPS receiver with access to the Louisiana State University C4G real-time network, which offers centimeterlevel measurement accuracy, was integrated with the terrestrial LiDAR to improve the localization accuracy. After the LiDAR scan, the GPS system collected 2634 points along seventy-six cross-berm transects with a 5-m cross-transect interval and half meter alongtransect interval and eleven more independent transects (six cross-berm and five alongberm transects) for accuracy assessment. All GPS surveys were conducted in the Louisiana South State Plane with a datum of NAD 1983 and with the North American Vertical Datum 1988 (NAVD 88) vertical datum.

\section{Methodology}

\subsection{Overview of an Adaptive Method for Terrain Correction}

This section presents an adaptive method to assign terrain correction factors in densely vegetated environments based on the crown structures obtained from terrestrial LiDAR, vegetation types from object-oriented classification and terrain samples from GPS data. The 
conceptual workflow includes three main stages, as illustrated in Figure 2. Stage 1 conducts terrestrial LiDAR scanning and generates an initial DEM following the procedures of multi-station registration, noise removal and site clipping, and an iterative ground filtering process. Stage 2 applies object-oriented classification based on the statistical raster layers produced from interpolation and statistical resampling of the unfiltered point cloud from stage 1 and compares it with pixel-based classification. Stage 3 corrects terrain for lowvegetation and tall-vegetation areas based on the classification result of stage 2 . To correct the terrain, the 95th percentile of errors correction factor is assigned to the digital surface model (DSM) in the low-vegetation area, and the regression-based adjusted correction factor is assigned to the DEM in the tall-vegetation area. The DSM captures both the natural and artificial features from the environment, and the DSM mainly represents the vegetation surface in this paper. The following sections illustrate and validate the application of this method through a densely vegetated coastal wetland restoration site.

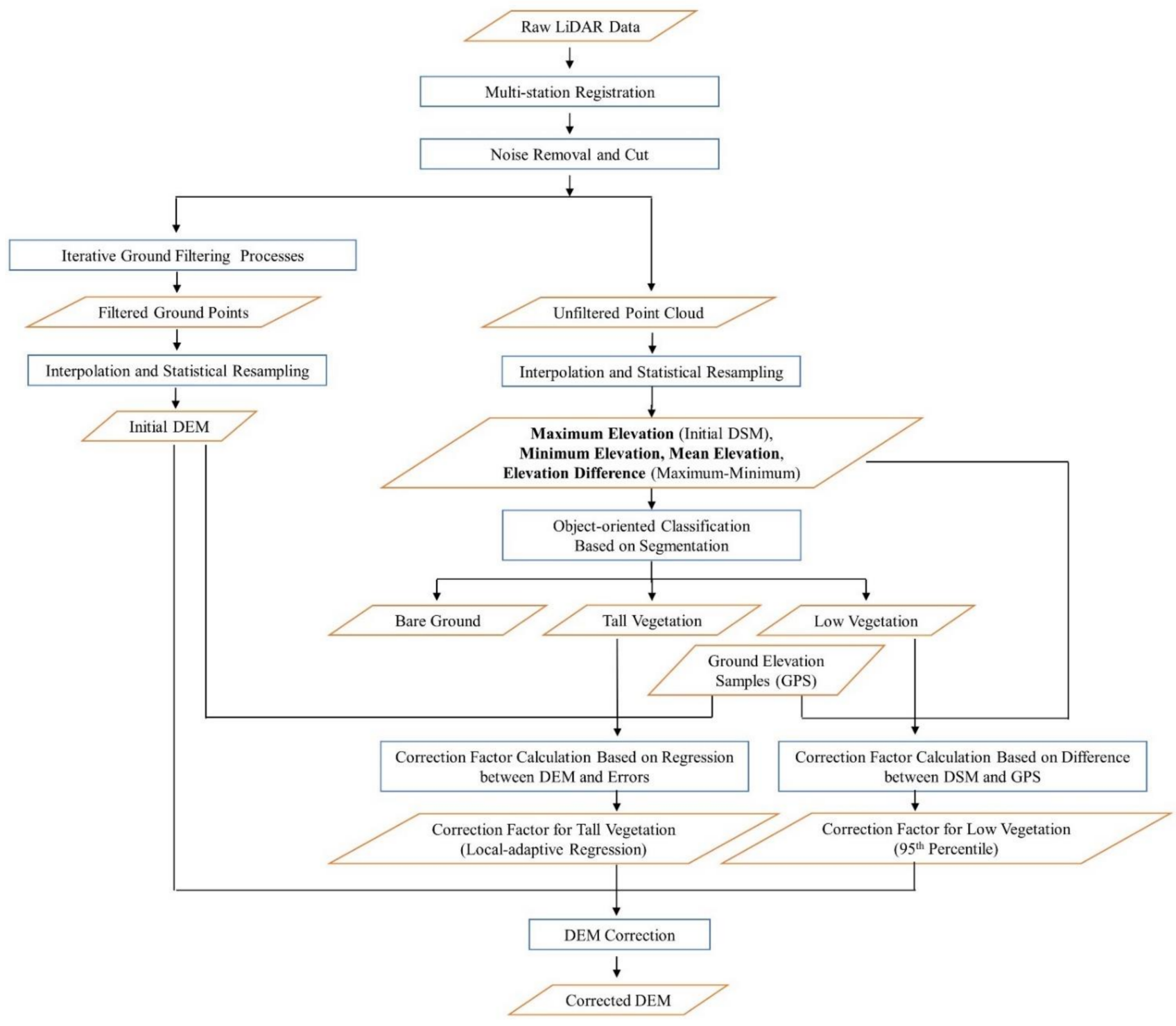

Figure 2. Workflow for DEM correction with the integration of GPS data.

\subsection{Stage 1: Initial DEM Generation}

Through tracking the time where a pulse occurred in a laser beam, as trigged by an object, LiDAR technology can measure the location of the object and, hence, produces dense point clouds with $X, Y$, and $Z$ coordinates for objects on or above the ground 
surface. The derived raw LiDAR point clouds from the multi-site scanning of typical coastal landscapes are a mixture of measurements from the ground, marshes, birds and boats, and from artificial facilities such as floating buoys and buildings, as well as other harbor infrastructure $[19,26,38]$. To generate DEM from these dense point surveys, points reflected from the ground surface need to be filtered first and then interpolated into 3-D terrain models of the terrain [39].

In this research, the processing of the collected terrestrial LiDAR data was performed using the RiSCAN PRO software, which is the companion software for RIEGL terrestrial LiDAR systems. A single scan results in millions of data points with $\mathrm{X}, \mathrm{Y}$ and $\mathrm{Z}$ coordinates and the point cloud can be viewed in $2 \mathrm{D}$ or $3 \mathrm{D}$ with color-coding by scanning range and point intensity to enhance the studied objects. After collecting all the terrestrial LiDAR data from the field, the first step of processing was to register all scan positions together through multi-station registration to the NAD 1983 Louisiana South Plane coordinate system. In this step, the performance of registration was dependent on the accuracy of the GPS associated with the terrestrial LiDAR and targets. Integrated with Louisiana State University's C4G real-time network, the GPS provided the ability to obtain highly accurate positions. Then, the second step was to remove noisy points manually and cut the whole dataset into the designated study site area. In RiSCAN PRO, the 3D scene of the point cloud allows users to rotate and view the point cloud from different angles. The noisy points, which are mainly caused by reflectance on small particles in the air or on unexpected objects such as birds and boats, clustered above the berm and on the nearby water surface. The noisy points were identified visually and removed manually by viewing them from different angles in the 3D scene. In this step, because of the huge data size, the noise removal was processed for each scan, respectively, instead of the whole dataset. All the clean data were merged for the next step of processing. Based on the results from the first two steps, an iterative process was applied, which was a combined function that included filtering, triangulation and separation, to generate point clouds for DEM. We performed the three-step iterative process by using the built-in functions in RiSCAN PRO, including the $2.5 \mathrm{D}$ raster filter, plane triangulation and surface comparison. Step 1: the function 2.5 D raster filter generated a rasterized point cloud by selecting the lowest point within each raster cell, which was decided based on the XY reference plane and the raster width. Step 2: the function plane triangulation created a meshed surface based on the point clouds from the $2.5 \mathrm{D}$ raster filter. Step 3: The function surface comparison used the meshed surface as a reference surface, and selected and removed the non-ground points in the point clouds located outside the distance threshold from the reference surface. The iterative process used an iteration of steps 1-3 with a reduction in the raster width in the $2.5 \mathrm{D}$ raster filter and a reduction in the distance threshold in the surface comparison. We conducted five iterations with parameters set up as shown in Table 1

Table 1. Parameters set up in the iterative process for removing non-ground points.

\begin{tabular}{ccc}
\hline Iterations & Raster Width $(\mathbf{m})$ & Distance Threshold (m) \\
\hline 1 & 10 & 15 \\
\hline 2 & 5 & 7 \\
\hline 3 & 2.5 & 3 \\
\hline 4 & 0.75 & 0.5 \\
\hline 5 & 0.5 & 0.1 \\
\hline
\end{tabular}

After removing the non-ground points from the iterative process, we produced a point cloud in *las format, with an average point spacing of $6 \mathrm{~cm}$, in Louisiana South State Plane, which had a datum of NAD 1983 and the North American Vertical Datum 1988 (NAVD 88 ) vertical datum. The point cloud was imported into ArcGIS to generate an initial raster DEM. The binning interpolation was previously proven to be an effective method to create 
raster images from LiDAR point clouds [40-42], and we set the type of cell assignment as minimum and the void fill method as natural neighbor for the binning interpolation. The cell size of the output DEM raster was chosen, based on the average point spacing of the point clouds, to be $6 \mathrm{~cm}[43,44]$.

\subsection{Stage 2: Object-Oriented Classification}

When applying terrestrial LiDAR in coastal environments, it is difficult for the laser signal to hit the ground by penetrating through dense vegetation. Our previous study showed that ground filtering is problematic in areas with a steep slope and dense or low vegetation [19]. Therefore, problems in this study site could potentially occur in areas that are densely covered by tall and short vegetation. For example, tall smooth cordgrass densely covered most areas along both sides of the sand berm, while seashore paspalum dominated mostly the middle to center part of the berm with higher elevation. A few other species originated from the soil and grew in relatively smaller populations after the first year of berm construction. The vegetation can cause different levels of uncertainty in the morphological modeling and, hence, should be quantified and corrected if possible.

Differences in the characteristics of vegetation, such as in height, density, etc., lead to different impacts on signal transmission. Therefore, DEM correction based on land cover classification is feasible. Hladik et al. (2013) [16] conducted a successful terrain correction in a saltmarsh by integrating airborne LiDAR data with hyperspectral images. They combined the classification with the LiDAR-derived DEM to correct elevation errors and reduced the overall mean error and root mean square error (RMSE) of the DEM. McClure et al. (2016) [45] applied correction factors to corresponding vegetation species and improved the vertical accuracy of a 1-m LiDAR-derived DEM using an RTK GPS dataset and local vegetation data within a tidal salt marsh.

In this study, the point cloud generated from the terrestrial LiDAR data was imported into ArcGIS 10.3 and interpolated into rasters. As a result, four rasters were derived from the interpolation, including maximum height, minimum height, mean height and height difference. The resolution of these rasters was consistent with that of the initial DEM as $6 \mathrm{~cm}$. All four rasters were imported into eCognition, a classification software package based on object-oriented information extraction technology, to conduct the object-oriented classification. As two main vegetation types prevailed on the berm, we can classify the whole study site into three classes: tall vegetation dominated by smooth cordgrass, low vegetation dominated by seashore paspalum, and other bare ground areas. Object-oriented classification is based on the information from a set of similar pixels called image objects and it outperforms pixel-based classification, in some cases, for the classification of highresolution images [46-50]. To compare it with pixel-based classification, a supervised classification using the support vector machine (SVM) classifier was conducted. SVM has been proven to be a robust and reliable method in many studies [51-54].

The first step of the object-oriented classification was a segmentation of the image, which produced image objects based on their spectral and textural characteristics. In this process, we used the algorithm of multi-resolution segmentation and spectral difference segmentation by equally weighting all four rasters. After the segmentation, a classification based on thresholds was applied for the bare ground. Training samples were selected randomly on the remaining unclassified objects for tall vegetation and low vegetation. Finally, based on these selected samples, a nearest neighbor classification was conducted. For pixel-based classification, a set of polygons (about 100 pixels per polygon) were randomly chosen on the berm as training samples for the SVM classifier.

To compare these two classification methods, we performed the accuracy assessment for classification using 47 samples for bare ground, 47 samples for low vegetation and 56 samples for tall vegetation (Figure 3). 


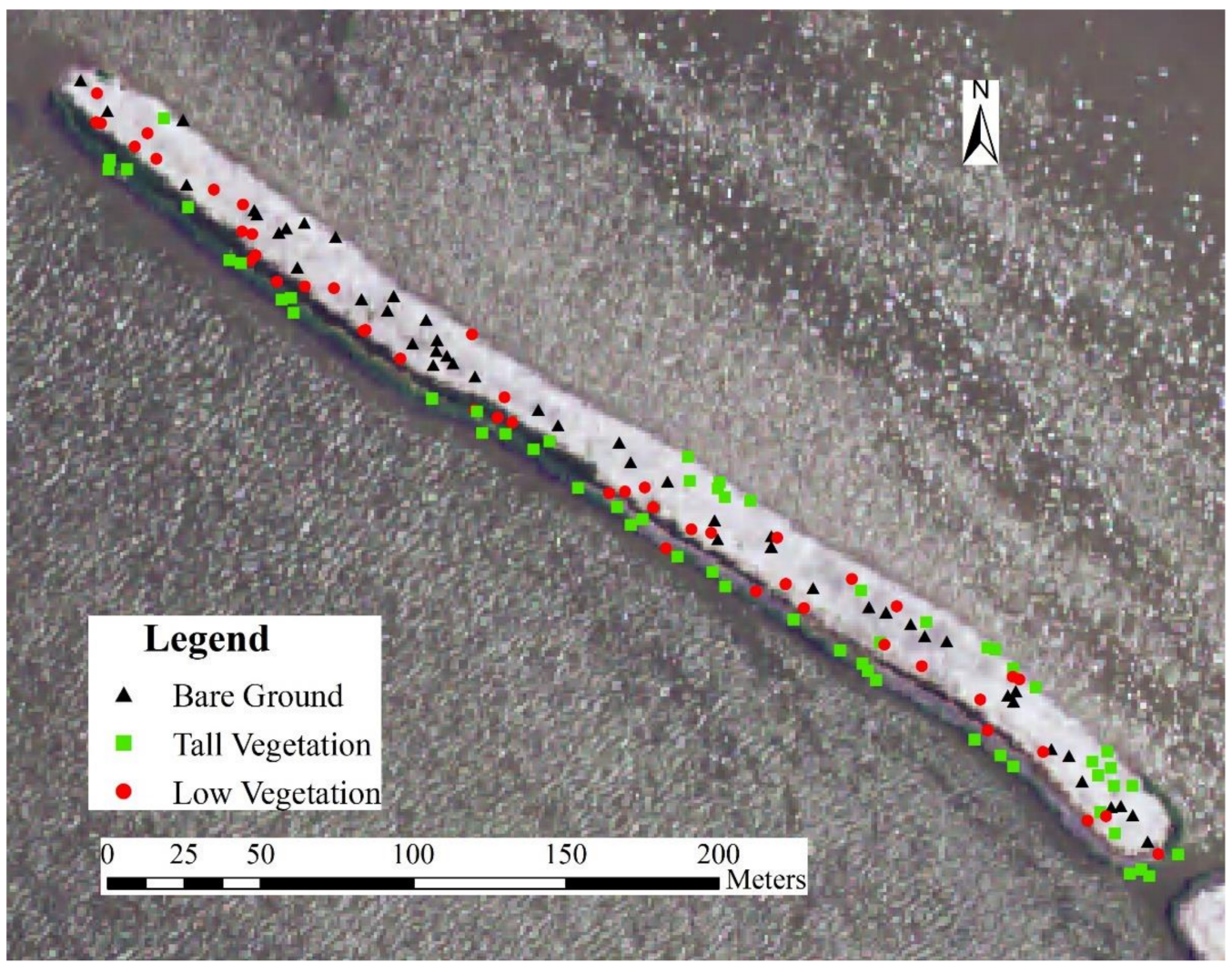

Figure 3. Samples distribution for accuracy assessment of classification.

\subsection{Stage 3: Terrain Correction}

\subsubsection{DEM Correction for Tall Vegetation}

DEM correction is necessary for areas that are covered by tall and dense vegetation due to the laser signal blockage. Filtering has been proven to be an efficient method to generate DEM in vegetated areas [40-42]. The filtering window can be adjusted according to the terrain complexity to guarantee that the signal can hit the ground and is received by the terrestrial LiDAR. However, adjustment of the window size is ineffective in large areas of dense vegetation due to lack of nearby ground, such as the study site in this research, resulting in significant overestimation of terrain. These errors need correction for all subsequent usage.

The density of the smooth cordgrass was high, but its height was relatively consistent. Correction factors can be applied to this kind of vegetation to improve the DEM. However, in this case, the height of the smooth cordgrass was around $2 \mathrm{~m}$, which was higher than the scan positions, leading to signal blockage between the scanner and the top of the vegetation. Consequently, the corrected DEM with the application of a global correction factor was lower than reality. To minimize the error based on these vegetation characteristics, this research applied an adaptive DEM correction factor for the areas that were covered by smooth cordgrass. Fan (2014) [32] explored the relationship between vegetation height and errors, and he found that the average penetration depth, which was equivalent to the difference between the grass height and vegetation error, was about 35\% of the grass height. Errors were derived by subtracting the surveyed GPS elevation from the DEM elevation at the corresponding $\mathrm{x} / \mathrm{y}$ coordinate. The grass height can be calculated by subtracting DEM from DSM, so that the errors correlate with the subtraction of DEM from DSM, and the equation is

Errors $=(1-35 \%) *(\mathrm{DSM}-\mathrm{DEM})=0.65 *(\mathrm{DSM}-\mathrm{DEM})=0.65 * \mathrm{DSM}-0.65 * \mathrm{DEM}$ 
Based on the above correlation, the calculation of errors is feasible and these errors are adaptive correction factors for DEM correction. In this research, the initial DEM and DSM were different from reality due to the signal blockage in dense, tall vegetation. Exploring a new correlation equation was necessary and the adaptive correction factors for this research were derived with the new equation.

\subsubsection{DEM Correction for Low Vegetation}

Compared with the smooth cordgrass, the seashore paspalum in the study site was lower, with an average height of $0.37 \mathrm{~m}$ based on the vegetation plot surveys, which was lower than the scanner's height. As a result, the laser signal launched from the scanner could hit the top of most vegetation for a more accurate DSM than DEM. However, most research applied correction factors based on DEM instead of DSM to correct the DEM when using airborne LiDAR data. Hladik and Alber (2012) [15] corrected the DEM in vegetated coastal environments using mean error as the correction factor and improved the accuracy of LiDAR-derived DEM. They calculated the mean errors for each land cover class by subtracting the GPS-surveyed elevation from the DEM and averaged them into one single correction factor.

To correct the DEM in the areas with low vegetation and relatively homogenous crown height, this research derived the correction factor based on DSM, meaning that the final DEM was produced by subtracting the correction factor from the DSM. In addition to the mean error, other statistical parameters, such as 75th percentile error and 95th percentile error, were tested as well. The correction factor with the highest accuracy was applied to correct the DEM. After the DEM correction for the areas with low and tall vegetation, respectively, the corrected DEMs were merged with the DEM of bare ground.

\section{Results and Discussion}

\subsection{Initial DEM Generation and Accuracy Assessment}

After the data processing in RiSCAN PRO, the resulting point cloud was imported into ArcGIS and interpolated into DEM with the resolution of $6 \mathrm{~cm}$. As the interpolation process generated artificial surface in blank areas near the edge of the berm, we delineated the berm according to the data coverage from the point cloud, and cut the initial DEM to the delineated shape. The raster DEM is shown in Figure 4.

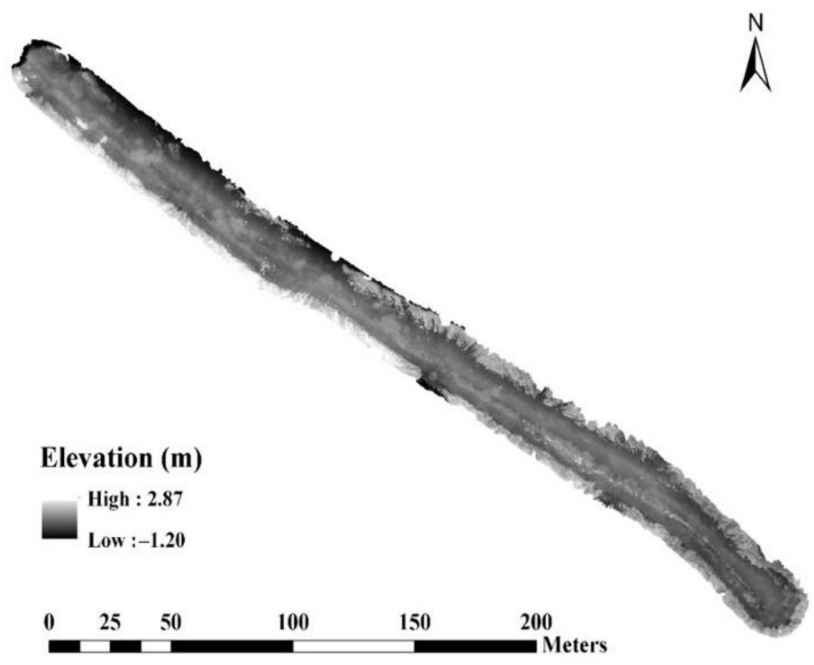

Figure 4. Initial DEM with the resolution of $6 \mathrm{~cm}$.

The elevation range of the initial DEM was $4.07 \mathrm{~m}$, which was much higher than reality. The overestimation was caused by the blockage of laser signal in the vegetated areas [55], especially in areas with tall vegetation. The signal could not travel through the dense vegetation to hit the ground, leading to a relatively higher elevation value than the 
actual ground surface. Due to the signal blocking by dense vegetation, the accuracy of the generated DEM was uncertain and it was necessary to conduct an accuracy assessment to evaluate the reliability of terrain mapping results and compare the accuracies before and after terrain correction [56]. Therefore, a set of GPS recordings was separately selected for bare ground, tall vegetation, and low vegetation along evenly distributed transects. As a result, 56 points on bare ground, 61 points on low vegetation and 55 points on tall vegetation were selected, respectively. These three sets of samples surveyed through the GPS receiver had an RMS of $0.016 \mathrm{~m}$ for horizontal accuracy and an RMS of $0.022 \mathrm{~m}$ for vertical accuracy.

Table 2 shows the results of accuracy assessment, where positive values indicate an overestimation of elevation values. For bare ground area, the mean error and standard deviation were $-0.003 \mathrm{~m}$ and $0.023 \mathrm{~m}$, respectively, demonstrating that the terrestrial LiDAR was capable of generating a reliable and accurate DEM without the influence of vegetation. Therefore, the DEM correction was not necessary for the bare ground areas. However, the mean errors in the low and tall vegetation were $0.377 \mathrm{~m}$ and $0.993 \mathrm{~m}$, respectively, which caused significant errors for subsequent morphological analysis [57]. Therefore, it can be concluded that DEM correction is necessary and critical for densely vegetated coastal environments [58].

Table 2. Elevation errors of the initial DEM generated from terrestrial LiDAR.

\begin{tabular}{ccccc}
\hline Land Cover & $\begin{array}{c}\text { Minimum } \\
(\mathbf{m})\end{array}$ & $\begin{array}{c}\text { Maximum } \\
(\mathbf{m})\end{array}$ & $\begin{array}{c}\text { Mean } \\
(\mathbf{m})\end{array}$ & $\begin{array}{c}\text { Standard Deviation } \\
(\mathbf{m})\end{array}$ \\
\hline Bare ground & -0.067 & 0.091 & -0.003 & 0.023 \\
\hline Low vegetation & -0.050 & 0.573 & 0.377 & 0.125 \\
\hline Tall vegetation & 0.043 & 1.783 & 0.993 & 0.397 \\
\hline
\end{tabular}

\subsection{Land Cover Classification}

The overall classification accuracies for object-oriented and pixel-based classification were $92.7 \%$ and $82.0 \%$, respectively, with kappa statistics of 0.89 and 0.73 . For objectoriented classification and pixel-based classification, the user's accuracy of individual classes ranged from $88.9 \%$ to $95.8 \%$ and from $60.8 \%$ to $97.9 \%$, and the producer's accuracy ranged from $88.9 \%$ to $96.9 \%$ and from $74.6 \%$ to $88.2 \%$, respectively. The accuracy assessment proved that the object-oriented method yielded a better classification result, with a higher overall accuracy and Kappa value. Both classification images are shown in Figures 5 and 6.

\subsection{DEM Correction for Tall Vegetation}

According to the accuracy analysis of the initial DEM, dense tall vegetation has significant impacts on mapping accuracy. The study site was classified into tall vegetation, low vegetation and bare ground. Based on the classification result, the DEM for tall and low vegetation was corrected separately. Previous research applied correction factors to modify the classified DEM and achieved a significant improvement $[15,16]$. This research applied an adaptive correction factor for tall vegetation based on local conditions. The adjusted correction factor was decided by exploring the correlation between errors and the initial DEM and DSM. The construction of correlation involved 800 GPS points in the tall vegetation to derive the adjusted correction factor. Equation (2) shows the correlation between errors and the initial DEM and DSM.

$$
\text { Errors }=1.055 * \text { DEM }-0.019 * \text { DSM }-0.284
$$

The $\mathrm{R}$ square of the regression equation was as high as 0.733; Figure 7 shows the points scattering. With the subtraction of the adjusted correction factor from the initial DEM for tall vegetation, DEM correction was achieved. Figure 8 shows the corrected DEM. 


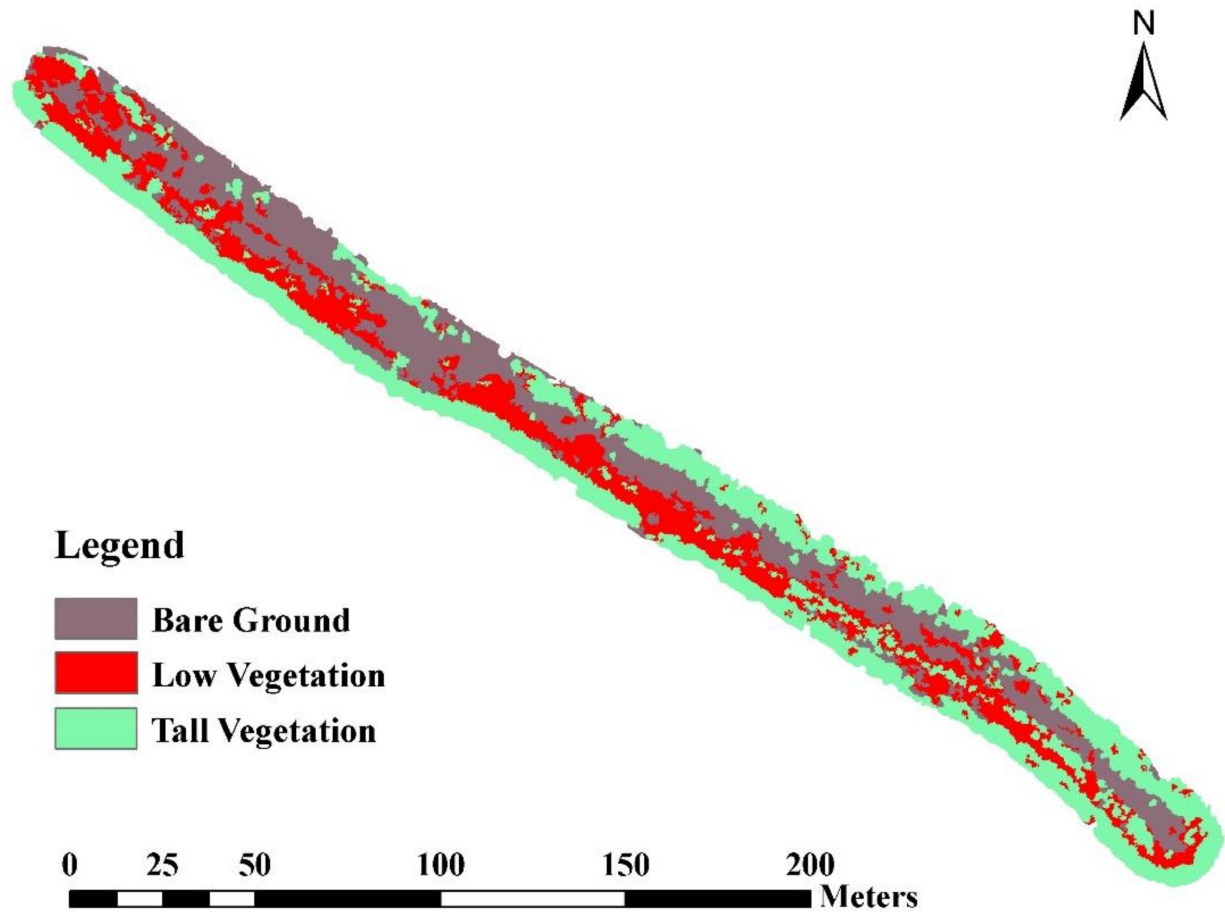

Figure 5. Classification result based on the object-oriented method.

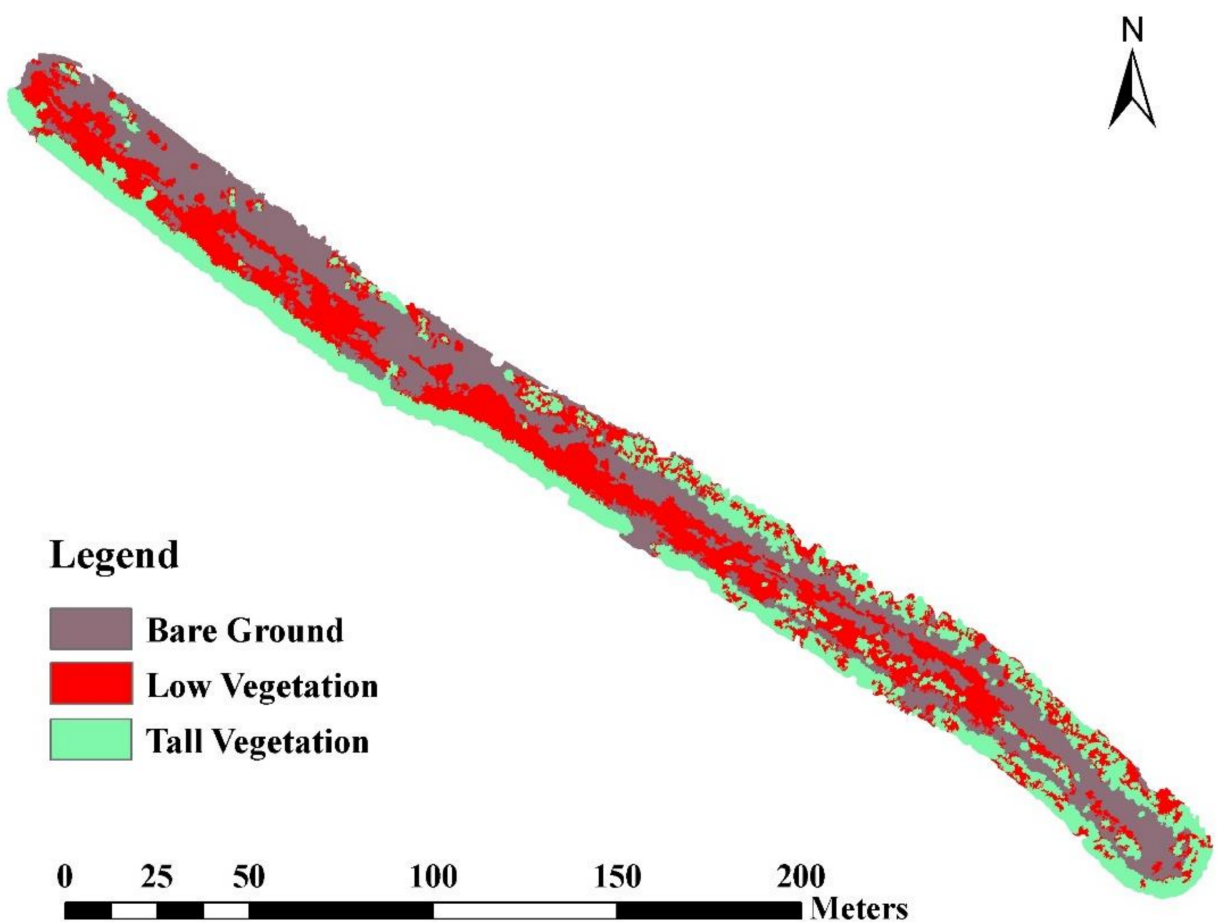

Figure 6. Classification result based on the pixel-based method. 


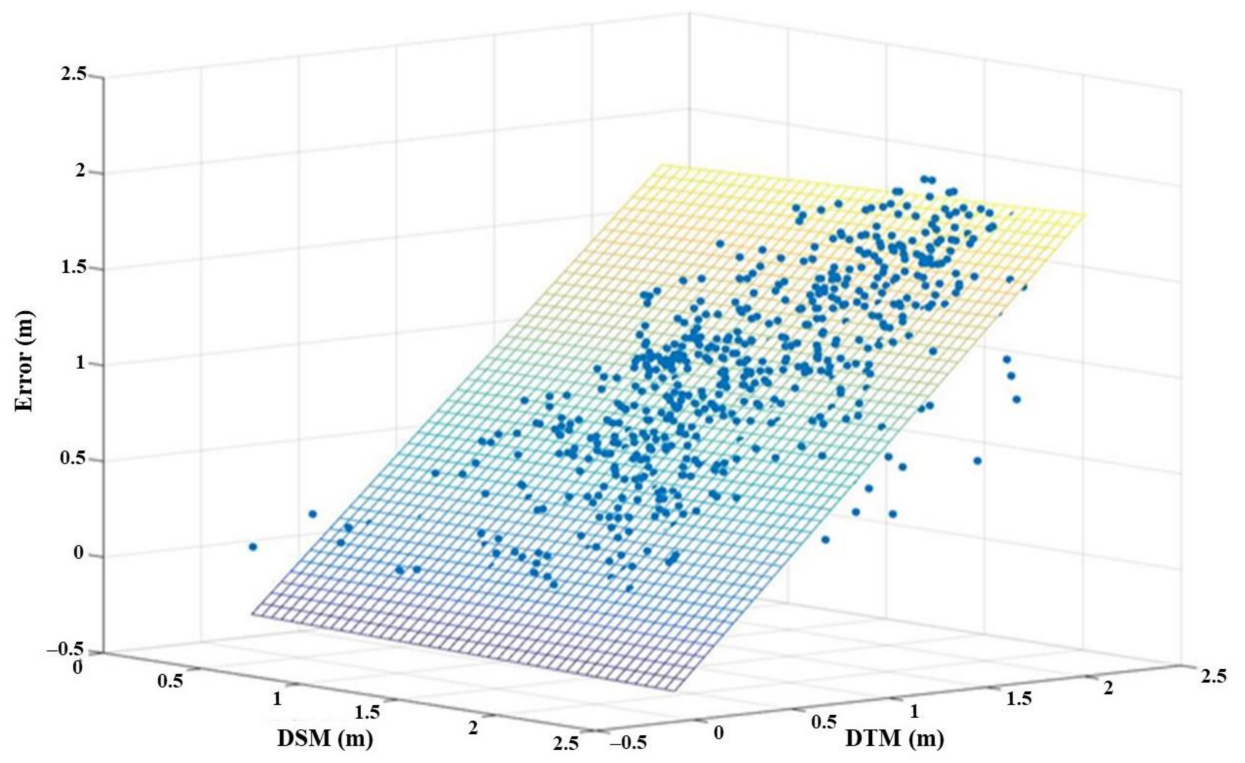

Figure 7. Relationship between errors and initial DEM and DSM.

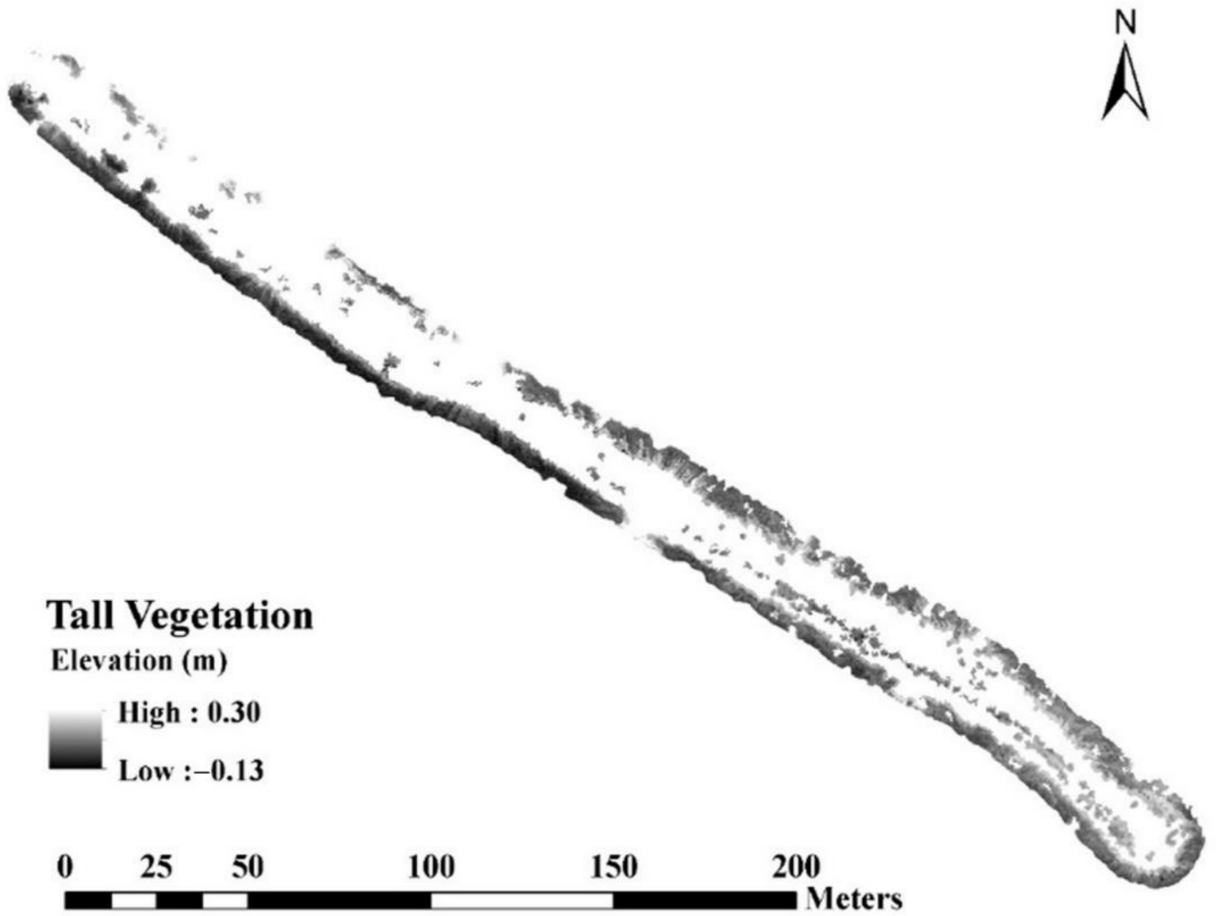

Figure 8. Corrected DEM for tall vegetation.

\subsection{DEM Correction for Low Vegetation}

In this research, the correction factor was calculated by subtracting the surveyed GPS data from the DSM elevation at the $\mathrm{x} / \mathrm{y}$ coordinate of the GCP and deriving the statistical parameter. The final elevation was obtained by subtracting the correction factor from the DSM elevation.

$$
\text { Final Elevation }=\text { DSM }- \text { Correction Factor }
$$

Representing the average difference between the DEM and GPS elevations, the mean error was previously applied as a correction factor to successfully modify the DEM [15]. The mean error works effectively when the vegetation condition in the study area is consistent, meaning that the errors caused by vegetation block do not vary widely. In this research, the low vegetation presented a diverse height, leading to a wide range of errors. Consequently, 
the DEM correction with mean error as the correction factor may generate a low-accuracy product. In addition to the mean error, two statistical parameters derived from errors (the 75th and 95th percentile error) were tested using the mean bias error (MBE) and RMSE. MBE quantifies the overall bias and detects if the corrected DEM produces overestimation $(\mathrm{MBE}>0)$ or underestimation $(\mathrm{MBE}<0)$. The DEM correction using the 95th percentile error $(0.58 \mathrm{~m})$ as the correction factor produced the highest-accuracy DEM with the lowest RMSE and absolute value of MBE among three correction factors (Table 3). We conducted the DEM correction for the low-vegetation area by applying the 95th percentile error as the correction factor and generated the corrected DEM (Figure 9). After the correction for both the tall-vegetation area and the low-vegetation area, all the corrected DEMs were merged into the final DEM (Figure 10).

Table 3. Accuracy assessment for DEM correction by different factors.

\begin{tabular}{ccc}
\hline Correction Factor & MBE $(\mathbf{m})$ & RMSE(m) \\
\hline Mean Error & 0.12 & 0.19 \\
\hline 75th Percentile Error & 0.10 & 0.17 \\
\hline 95th Percentile Error & -0.06 & 0.15 \\
\hline
\end{tabular}

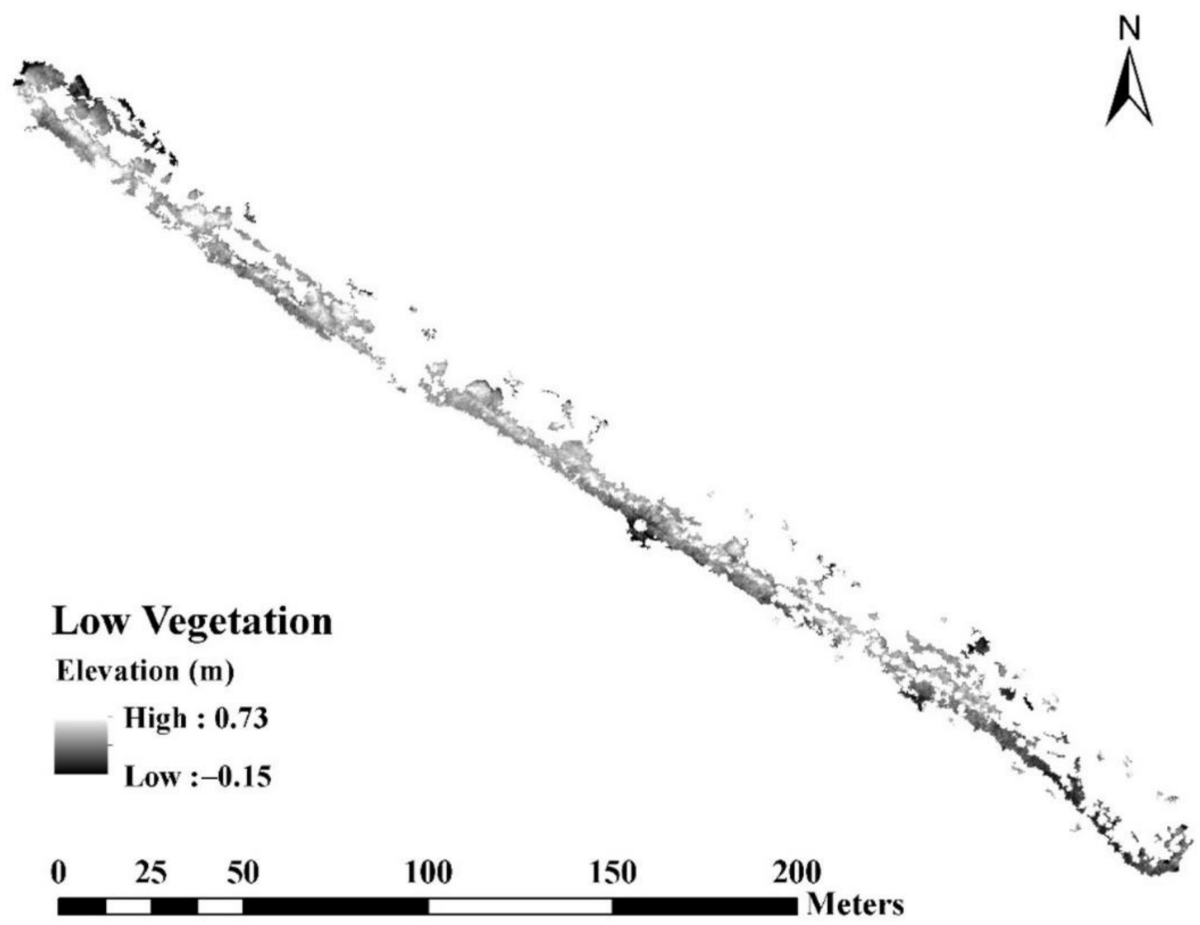

Figure 9. Corrected DEM for low vegetation. 


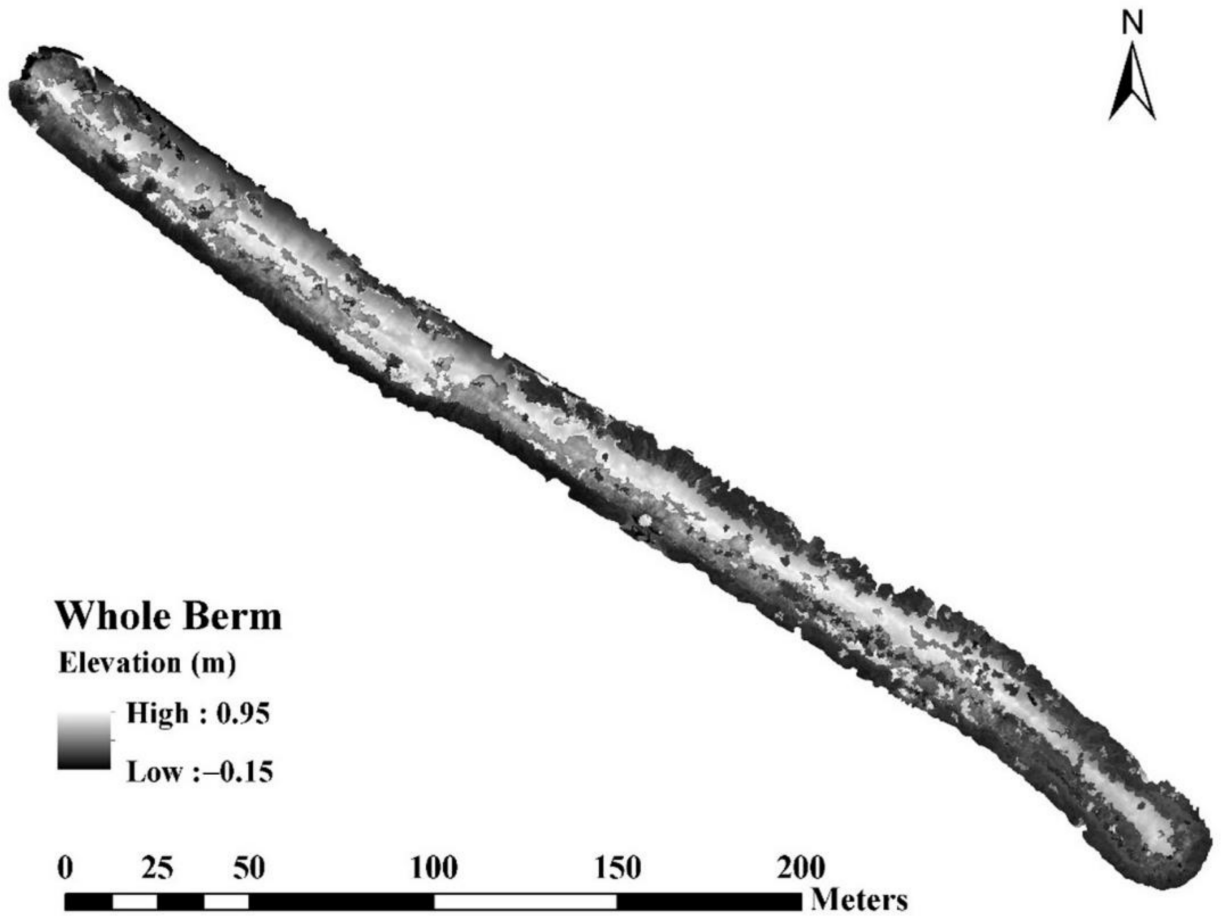

Figure 10. Corrected DEM for the whole study site.

\subsection{Application of Existing Correction Methods}

Filtering has been proven to be an efficient method to generate DEM in vegetated areas $[59,60]$. The filtering window can be adjusted to the terrain complexity so that the signal can hit the ground and be received by the terrestrial LiDAR. Adjusting the window size is an alternative method to filter the ground in the vegetated area. A larger window size could increase the chance of finding a nearby ground and, therefore, could reduce the error in the estimation of ground elevation. However, this will sacrifice topographical detail. The accuracy and the spatial characteristics of the terrain surface need to be balanced when selecting the window size [34]. The manner in which the filter window size impacts the accuracy of DEM correction was studied for areas with low vegetation and tall vegetation, respectively. The window size was initially set as $6 \times 6 \mathrm{~cm}^{2}$, the same resolution as DEM, and then it was increased from $10 \times 10 \mathrm{~cm}^{2}$ to $100 \times 100 \mathrm{~cm}^{2}$. The accuracy of the corrected DEMs at each window size was assessed for low-vegetated and tall-vegetated areas, respectively, and compared with the results achieved by our methods.

For the tall-vegetation area, the RMSE and MBE decreased gradually with the increase in the filtering window size, except at $10 \mathrm{~cm}$, where the maximum errors were present. Even when the window size was set at $100 \mathrm{~cm}$, the RMSE and MBE were still $0.63 \mathrm{~m}$ and $0.76 \mathrm{~m}$, respectively (Figure 11), which were too high for topographical analysis, in addition to a significant reduction in topographical detail. By contrast, the RMSE and MBE were reduced to $0.17 \mathrm{~m}$ and $-0.10 \mathrm{~m}$ using the proposed method, with a $6-\mathrm{cm}$ window size (Figure 11). The RMSE and MBE for the low-vegetation area showed the same trend as those for the tall-vegetation area. With the application of our method, the RMSE and MBE were also significantly improved to $0.15 \mathrm{~m}$ and $-0.06 \mathrm{~m}$ (Figure 12). 


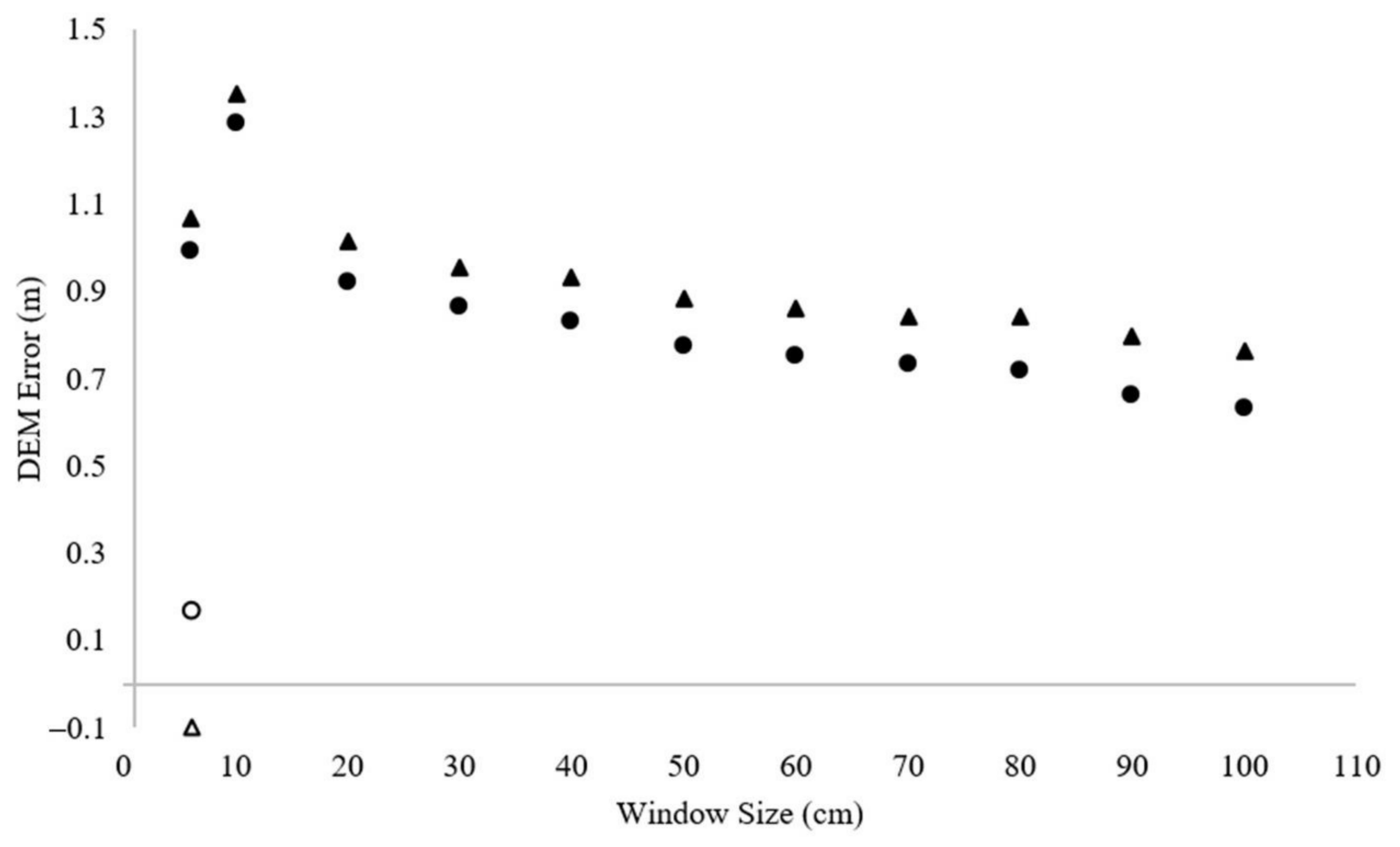

- RMSE $\triangle$ MBE O RMSE of Our Method $\triangle$ MSE of Our Method

Figure 11. Error comparison for tall vegetation between results obtained via the adjustment of window sizes and those obtained using our method.

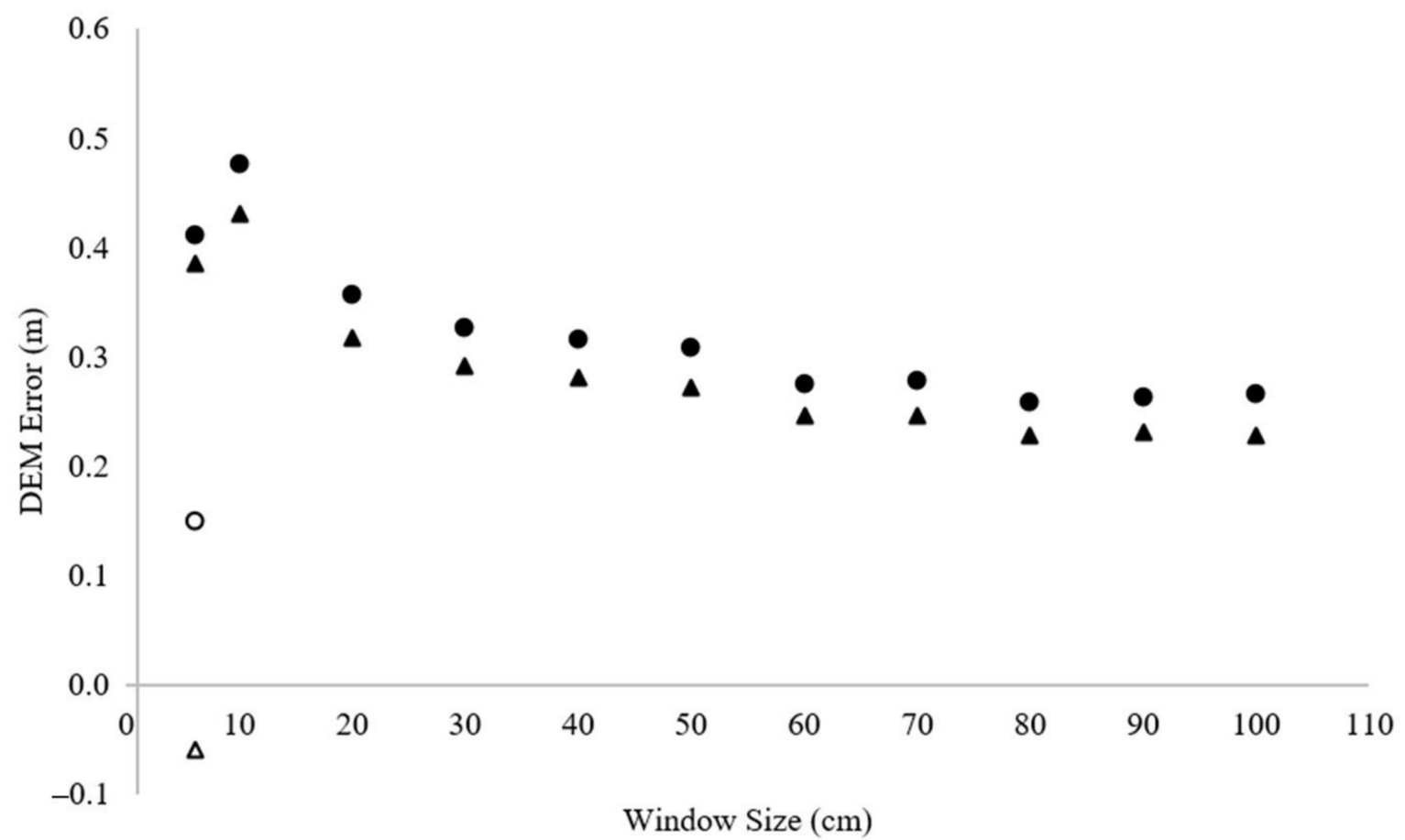

- RMSE $\triangle$ MBE O RMSE of Our Method $\triangle$ MBE of Our Method

Figure 12. Error comparison for low vegetation between results obtained via the adjustment of window sizes and those obtained using our method. 


\section{Conclusions}

This paper introduces a rapid and flexible terrain mapping solution for densely vegetated environments by integrating crown structures from terrestrial LiDAR with terrain samples from GPS. An iterative ground filtering process first generated the initial DEM with significant overestimation in low and tall vegetation. A terrain correction process classified the landscape based on the segmentation and the supervised SVM classification method, then corrected the terrain in vegetated areas based on the errors from the training samples in the corresponding class.

To improve the accuracy through incorporating vegetation characteristics, this research proposed a terrain correction method that assigns correction factors through a linear regression with DEM in tall vegetation and through the 95th percentile terrain error in low vegetation.

One major challenge in this research is the land-cover classification based on terrestrial LiDAR, without dependence on historical data or other images, which is critical for the ever-changing coastal landscapes. The object-oriented classification with four statistic rasters as inputs can separate the land cover into tall vegetation, low vegetation and bare ground, which is the basis for the next step of DEM correction. In the process of the objectoriented classification, a threshold-based classification separated bare ground from low and tall vegetation after the segmentation. Then, a supervised SVM classification classified the remaining objects into low and tall vegetation. The overall accuracy and kappa value for object-oriented classification were $92.7 \%$ and 0.89 , compared to $82.0 \%$ and 0.73 from the pixel-based classification method. The results demonstrate that the object-oriented method can yield a better classification result. Another challenge of applying this terrain correction method is the workload of GPS data collection. In this research, the collection of thousands of GPS points constituted a two-day workload and, in future studies, we will examine the impact of the reduction in GPS points on the final DEM performance. Other than the GPS data collection, noise removal is another time-consuming process and the automatic removal of noisy points may accelerate the processing as a whole.

Based on the classification results, we conducted DEM correction separately for low vegetation and tall vegetation. For tall vegetation, a statistical correlation between the error and the original DEM and DSM was applied to correct the DEM. For low vegetation, we corrected the terrain by subtracting the 95th percentile error correction factor from the DSM elevation. Both corrected DEMs showed better results than those corrected by the existing method of adjusting the filter window size. The terrain correction method successfully reduced the mean error from $0.407 \mathrm{~m}$ to $-0.068 \mathrm{~m}$ (RMSE errors from $0.425 \mathrm{~m}$ to $0.146 \mathrm{~m}$ ) in low vegetation and from $0.993 \mathrm{~m}$ to $-0.098 \mathrm{~m}$ (RMSE from $1.070 \mathrm{~m}$ to $0.144 \mathrm{~m}$ ) in tall vegetation. With the high resolution of $6 \mathrm{~cm}$ and high accuracy, the corrected DEM is a reliable data source for further coastal morphological analysis.

Author Contributions: Xukai Zhang developed the algorithm, processed the data and wrote the initial draft; Xuelian Meng helped to design the field data collection, process the data and refine the manuscript; Chunyan Li supported the study through leading the collaborative wetland restoration project and contributed to the writing of the manuscript; Nan Shang, Jiaze Wang and Yaping Xu contributed to the writing of the manuscript; Tao Wu and Cliff Mugnier contributed to the field data collection and the writing of the manuscript. All authors have read and agreed to the published version of the manuscript.

Funding: Funding for this work was provided by Martin Ecosystems through Buras wetland restoration project.

Data Availability Statement: Not applicable.

Acknowledgments: Acquisition of the terrestrial LiDAR system was supported by the Office of Research \& Economic Development (ORED), Louisiana State University. Access to C4G real-time network is supported by LSU Center for Geoinformatics.

Conflicts of Interest: The authors declare no conflict of interest. 


\section{References}

1. Almeida, L.P.; Almar, R.; Bergsma, E.W.; Berthier, E.; Baptista, P.; Garel, E.; Dada, O.A.; Alves, B. Deriving high spatial-resolution coastal topography from sub-meter satellite stereo imagery. Remote Sens. 2019, 11, 590. [CrossRef]

2. Mancini, F.; Dubbini, M.; Gattelli, M.; Stecchi, F.; Fabbri, S.; Gabbianelli, G. Using unmanned aerial vehicles (uav) for highresolution reconstruction of topography: The structure from motion approach on coastal environments. Remote Sens. 2013, 5, 6880-6898. [CrossRef]

3. Webster, T.L.; Forbes, D.L.; Dickie, S.; Shreenan, R. Using topographic lidar to map flood risk from storm-surge events for Charlottetown, Prince Edward Island, Canada. Can. J. Remote Sens. 2004, 30, 64-76. [CrossRef]

4. Mentaschi, L.; Vousdoukas, M.I.; Pekel, J.-F.; Voukouvalas, E.; Feyen, L. Global long-term observations of coastal erosion and accretion. Sci. Rep. 2018, 8, 1-11. [CrossRef]

5. Masselink, G.; Pattiaratchi, C.B. Seasonal changes in beach morphology along the sheltered coastline of perth, western australia. Mar. Geol. 2001, 172, 243-263. [CrossRef]

6. Dail, H.J.; Merrifield, M.A.; Bevis, M. Steep beach morphology changes due to energetic wave forcing. Mar. Geol. 2000, 162, 443-458. [CrossRef]

7. Coops, H.; Geilen, N.; Verheij, H.J. Interactions between waves, bank erosion and emergent vegetation: An experimental study in a wave tank. Aquat. Bot. 1996, 53, 187-198. [CrossRef]

8. Palmsten, M.L.; Holman, R.A. Laboratory investigation of dune erosion using stereo video. Coast. Eng. 2012, 60, 123-135. [CrossRef]

9. Erikson, L.H.; Hanson, H. A method to extract wave tank data using video imagery and its comparison to conventional data collection techniques. Comput. Geosci. 2005, 31, 371-384. [CrossRef]

10. Zhao, Q.; Bai, J.; Huang, L. A review of methodologies and success indicators for coastal wetland restoration. Ecol. Indic. 2016, 60, 442-452. [CrossRef]

11. Jangir, B.; Satyanarayana, A.N.V.; Swati, S. Delineation of spatio-temporal changes of shoreline and geomorphological features of Odisha coast of India using remote sensing and GIS techniques. Nat. Hazards 2016, 82, 1437-1455. [CrossRef]

12. Holland, K.T.; Puleo, J.A.; Kooney, T.N. Quantification of swash flows using video-based particle image velocimetry. Coast. Eng. 2001, 44, 65-77. [CrossRef]

13. Dixon, T.H.; Amelung, F.; Ferretti, A. Space geodesy: Subsidence and flooding in New Orleans. Nature 2006, 441, 587-588. [CrossRef]

14. Houser, C.; Hapke, C.; Hamilton, S. Controls on coastal dune morphology, shoreline erosion and barrier island response to extreme storms. Geomorphology 2008, 100, 223-240. [CrossRef]

15. Hladik, C.; Alber, M. Accuracy assessment and correction of a LIDAR-derived salt marsh digital elevation model. Remote Sens. Environ. 2012, 121, 224-235. [CrossRef]

16. Hladik, C.; Schalles, J.; Alber, M. Salt marsh elevation and habitat mapping using hyperspectral and lidar data. Remote Sens. Environ. 2013, 139, 318-330. [CrossRef]

17. Su, J.; Bork, E. Influence of vegetation, slope, and lidar sampling angle on dem accuracy. Photogramm. Eng. Remote. Sens. 2006, 72, 1265-1274. [CrossRef]

18. Heritage, G.; Hetherington, D. Towards a protocol for laser scanning in fluvial geomorphology. Earth Surf. Process. Landf. 2007, 32, 66-74. [CrossRef]

19. Meng, X.L.; Wang, L.; Silvan-Cardenas, J.L. A multi-directional ground filtering algorithm for airborne LIDAR. ISPRS J. Photogramm. Remote Sens. 2009, 64, 117-124. [CrossRef]

20. Meng, X.L.; Currit, N.; Zhao, K.G. Ground Filtering Algorithms for Airborne LiDAR Data: A Review of Critical Issues. Remote Sens. 2010, 2, 833-860. [CrossRef]

21. Hebeler, F.; Purves, R.S. The influence of elevation uncertainty on derivation of topographic indices. Geomorphology 2009, 111, 4-16. [CrossRef]

22. Hutton, C.; Brazier, R. Quantifying riparian zone structure from airborne lidar: Vegetation filtering, anisotropic interpolation, and uncertainty propagation. J. Hydrol. 2012, 442-443, 36-45. [CrossRef]

23. Chen, Q.; Vaglio Laurin, G.; Valentini, R. Uncertainty of remotely sensed aboveground biomass over an african tropical forest: Propagating errors from trees to plots to pixels. Remote Sens. Environ. 2015, 160, 134-143. [CrossRef]

24. Hopkinson, C.; Chasmer, L.; Hall, R.J. The uncertainty in conifer plantation growth prediction from multi-temporal lidar datasets. Remote Sens. Environ. 2008, 112, 1168-1180. [CrossRef]

25. Mascaro, J.; Detto, M.; Asner, G.P. Evaluating uncertainty in mapping forest carbon with airborne LiDAR. Remote Sens. Environ. 2011, 115, 3770-3774. [CrossRef]

26. Meng, X.; Zhang, X.; Silva, R.; Li, C.; Wang, L. Impact of high-resolution topographic mapping on beach morphological analyses based on terrestrial LiDAR and object-oriented beach evolution. ISPRS Int. J. Geo-Inf. 2017, 6, 147. [CrossRef]

27. Moser, K.; Ahn, C.; Noe, G. Characterization of microtopography and its influence on vegetation patterns in created wetlands. Wetlands 2007, 27, 1081-1097. [CrossRef]

28. Moser, K.F.; Ahn, C.; Noe, G.B. The Influence of Microtopography on Soil Nutrients in Created Mitigation Wetlands. Restor. Ecol. 2009, 17, 641-651. [CrossRef] 
29. Pollock, M.M.; Naiman, R.J.; Hanley, T.A. Plant species richness in riparian wetlands-A test of biodiversity theory. Ecology 1998, 79, 94-105.

30. Karstens, S.; Jurasinski, G.; Glatzel, S.; Buczko, U. Dynamics of surface elevation and microtopography in different zones of a coastal phragmites wetland. Ecol. Eng. 2016, 94, 152-163. [CrossRef]

31. Coveney, S.; Fotheringham, A.S. Terrestrial laser scan error in the presence of dense ground vegetation. Photogramm. Rec. 2011, 26, 307-324. [CrossRef]

32. Fan, L. Uncertainty in Terrestrial Laser Scanning for Measuring Surface Movements at a Local Scale; University of Southampton: Southampton, UK, 2014.

33. Guarnieri, A.; Vettore, A.; Pirotti, F. Retrieval of small-relief marsh morphology from Terrestrial Laser Scanner, optimal spatial filtering, and laser return intensity. Geomorphology 2009, 113, 12-20. [CrossRef]

34. Rodriguez-Caballero, E.; Afana, A.; Chamizo, S.; Sole-Benet, A.; Canton, Y. A new adaptive method to filter terrestrial laser scanner point clouds using morphological filters and spectral information to conserve surface micro-topography. ISPRS J. Photogramm. 2016, 117, 141-148. [CrossRef]

35. Che, E.Z.; Olsen, M.J. Fast ground filtering for TLS data via Scanline Density Analysis. ISPRS J. Photogramm. Remote Sens. 2017, 129, 226-240. [CrossRef]

36. Theriot, J.P. American Energy, Imperiled Coast: Oil and Gas Development in Louisiana's Wetlands; Louisiana State University Press: Baton Rouge, LA, USA, 2014.

37. Morton, R.A.; Bernier, J.C.; Barras, J.A. Evidence of regional subsidence and associated interior wetland loss induced by hydrocarbon production, Gulf Coast region, USA. Environ. Geol. 2006, 50, 261-274. [CrossRef]

38. Zhao, K.G.; Garcia, M.; Liu, S.; Guo, Q.H.; Chen, G.; Zhang, X.S.; Zhou, Y.Y.; Meng, X.L. Terrestrial lidar remote sensing of forests: Maximum likelihood estimates of canopy profile, leaf area index, and leaf angle distribution. Agric. For. Meteorol. 2015, 209, 100-113. [CrossRef]

39. Meng, X.L.; Currit, N.; Wang, L.; Yang, X.J. Detect residential buildings from lidar and aerial photographs through object-oriented land-use classification. Photogramm. Eng. Rem. Sens. 2012, 78, 35-44. [CrossRef]

40. Bindzarova Gergelova, M.; Labant, S.; Mizak, J.; Sustek, P.; Leicher, L. Inventory of Locations of Old Mining Works Using LiDAR Data: A Case Study in Slovakia. Sustainability 2021, 13, 6981. [CrossRef]

41. Li, L.; Nearing, M.A.; Nichols, M.H.; Polyakov, V.O.; Guertin, D.P.; Cavanaugh, M.L. The effects of DEM interpolation on quantifying soil surface roughness using terrestrial LiDAR. Soil Tillage Res. 2020, 198, 104520. [CrossRef]

42. Cățeanu, M.; Ciubotaru, A. The effect of lidar sampling density on DTM accuracy for areas with heavy forest cover. Forests 2021, 12, 265. [CrossRef]

43. Langridge, R.M.; Ries, W.F.; Farrier, T.; Barth, N.C.; Khajavi, N.; De Pascale, G.P. Developing sub 5-m LiDAR DEMs for forested sections of the Alpine and Hope faults, South Island, New Zealand: Implications for structural interpretations. J. Struct. Geol. 2014, 64, 53-66. [CrossRef]

44. Shi, W.; Deng, S.; Xu, W. Extraction of multi-scale landslide morphological features based on local Gi* using airborne LiDARderived DEM. Geomorphology 2018, 303, 229-242. [CrossRef]

45. McClure, A.; Liu, X.H.; Hines, E.; Ferner, M.C. Evaluation of error reduction techniques on a lidar-derived salt marsh digital elevation model. J Coast. Res 2016, 32, 424-433.

46. Gao, Y.; Mas, J.F.; Maathuis, B.H.P.; Zhang, X.M.; Van Dijk, P.M. Comparison of pixel-based and object-oriented image classification approaches-A case study in a coal fire area, wuda, inner mongolia, china. Int. J. Remote Sens. 2006, 27, 4039-4055.

47. Yu, Q.; Gong, P.; Clinton, N.; Biging, G.; Kelly, M.; Schirokauer, D. Object-based detailed vegetation classification. With airborne high spatial resolution remote sensing imagery. Photogramm. Eng. Rem. Sens. 2006, 72, 799-811. [CrossRef]

48. Platt, R.V.; Rapoza, L. An evaluation of an object-oriented paradigm for land use/land cover classification. Prof. Geogr. 2008, 60, 87-100. [CrossRef]

49. Myint, S.W.; Gober, P.; Brazel, A. Per-pixel vs. object-based classification of urban land cover extraction using high spatial resolution imagery. Remote Sens. Environ. 2011, 115, 1145-1161. [CrossRef]

50. Duro, D.C.; Franklin, S.E.; Dube, M.G. A comparison of pixel-based and object-based image analysis with selected machine learning algorithms for the classification of agricultural landscapes using spot-5 hrg imagery. Remote Sens. Environ. 2012, 118, 259-272. [CrossRef]

51. Liu, Q.J.; Jing, L.H.; Wang, M.F.; Lin, Q.Z. Hyperspectral remote sensing image classification based on svm optimized by clonal selection. Spectrosc. Spect. Anal. 2013, 33, 746-751.

52. Niu, X.; Ban, Y.F. Multi-temporal radarsat-2 polarimetric sar data for urban land-cover classification using an object-based support vector machine and a rule-based approach. Int. J. Remote Sens. 2013, 34, 1-26. [CrossRef]

53. Pal, M.; Mather, P.M. Support vector machines for classification in remote sensing. Int. J. Remote Sens. 2005, $26,1007-1011$. [CrossRef]

54. Zhang, C.Y.; Xie, Z.X. Data fusion and classifier ensemble techniques for vegetation mapping in the coastal everglades. Geocarto Int. 2014, 29, 228-243. [CrossRef]

55. Fan, L.; Powrie, W.; Smethurst, J.; Atkinson, P.M.; Einstein, H. The effect of short ground vegetation on terrestrial laser scans at a local scale. ISPRS J. Photogramm. 2014, 95, 42-52. [CrossRef] 
56. Meng, X.; Shang, N.; Zhang, X.; Li, C.; Zhao, K.; Qiu, X.; Weeks, E. Photogrammetric UAV mapping of terrain under dense coastal vegetation: An object-oriented classification ensemble algorithm for classification and terrain correction. Remote Sens. 2017, 9, 1187. [CrossRef]

57. Milan, D.J.; Heritage, G.L.; Large, A.R.; Fuller, I.C. Filtering spatial error from DEMs: Implications for morphological change estimation. Geomorphology 2011, 125, 160-171. [CrossRef]

58. Cooper, H.M.; Zhang, C.; Davis, S.E.; Troxler, T.G. Object-based correction of LiDAR DEMs using RTK-GPS data and machine learning modeling in the coastal Everglades. Environ. Model. Softw. 2019, 112, 179-191. [CrossRef]

59. Streutker, D.R.; Glenn, N.F. LiDAR measurement of sagebrush steppe vegetation heights. Remote Sens. Environ. 2006, 102, 135-145. [CrossRef]

60. Wang, C.; Menenti, M.; Stoll, M.P.; Feola, A.; Belluco, E.; Marani, M. Separation of ground and low vegetation signatures in lidar measurements of salt-marsh environments. IEEE Trans. Geosci. Remote Sens. 2009, 47, 2014-2023. [CrossRef] 